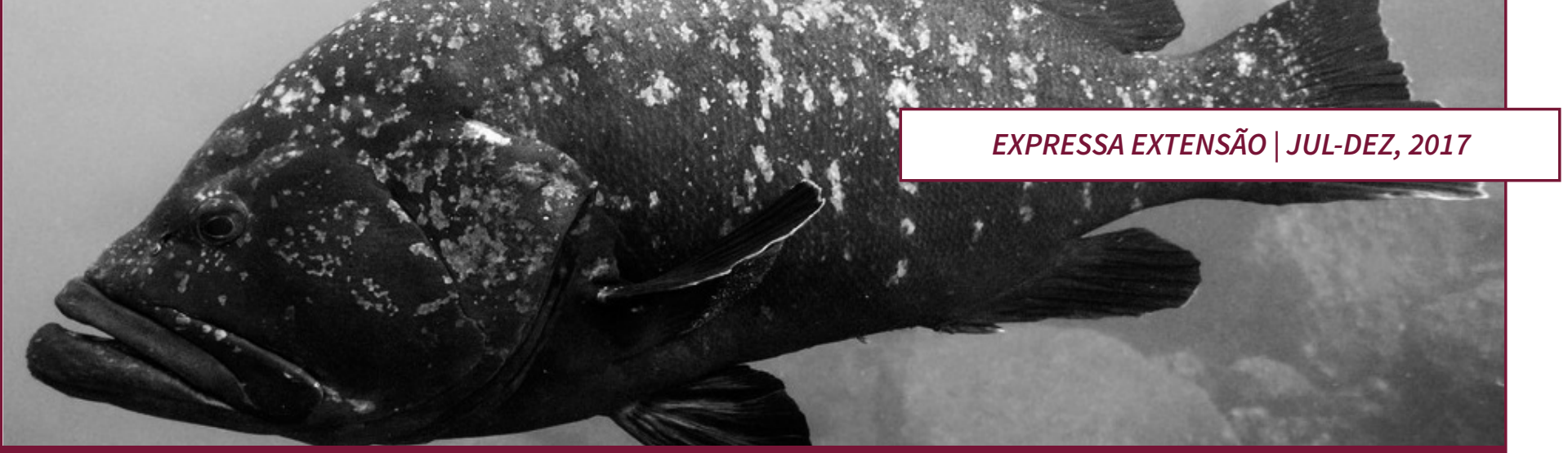

\title{
A EDUCAÇÃO AMBIENTAL E A EXTENSÃO NA UNIVERSIDADE: UM BREVE OLHAR SOBRE A GAROUPA VERDADEIRA (Epinephelus marginatus) E OS PEI- XES COSTEIROS NO EXTREMO SUL DO BRASIL
}

THE ENVIRONMENTAL EDUCATION AND THE EXTENSION INTO UNIVERSITY: A BRIEF LOOK ABOUT THE DUSKY GROUPER (Epinephelus marginatus) AND COASTAL FISHES AT THE EXTREME SOUTH OF BRAZIL

Kerolen Rosa das Neves ${ }^{1} \quad$ Mario Vinicius Condini ${ }^{2} \quad$ Alexandre Miranda Garcia $^{3}$ Joziel Gonçalves Botelho ${ }^{4}$

Dentre os impactos antrópicos mais comuns sobre os ecossistemas marinhos e costeiros, podemos citar a instalação de indústrias próximas à zona costeira, poluição, sobre pesca e destruição dos habitats. Uma forma de problematizar e discutir como o homem tem se relacionado com os mares é promover no ambiente escolar um espaço aberto para debates, exposições de ideias e questionamentos. Buscamos, assim, desenvolver diferentes metodologias em torno de peixes costeiros com enfoque na garoupa-verdadeira (Epinephelus marginatus), que intentam estimular o desenvolvimento de estudantes com uma leitura crítica da realidade do município em que vivem, a fim de tornar mais profícuo e enriquecedor o processo de ensino e aprendizagem. Neste enquadramento, o presente trabalho traz também algumas discussões acerca de como a Educação Ambiental e a extensão têm-se colocado na universidade. Sendo o município do Rio Grande/ RS cenário de diferentes conflitos ambientais, procurou-se elaborar estratégias educacionais que fossem de encontro a essas problemáticas que estão intimamente relacionadas com as vivências dos estudantes.

Palavras-chave: Impactos antrópicos. Extensão. Conflitos ambientais.

'Kerolen Rosa das Neves - Graduada em Ciências Biológicas Licenciatura pela Universidade Federal do Rio Grande, departamento de Ciências Biológicas. E-mail: kerolendasneves@gmail.com; 2Mario Vinicius Condini - Graduado em Oceanologia na Universidade Federal do Rio Grande - FURG, mestrado pelo Programa de Pós-Graduação em Oceanografia Biológica da FURG, doutorado pelo mesmo programa, com período sanduíche na Faculdade de Ciências da Universidade de Lisboa. Atualmente é bolsista de Pós-Doutorado no Instituto de Oceanografia - FURG. E-mail: mvcondini@gmail.com; ${ }^{3}$ Alexandre Miranda Garcia - Possui graduação em Oceanologia pela Fundação Universidade Federal do Rio Grande- FURG, mestrado e doutorado em Oceanografia Biológica pela FURG e pós-doutorado pela Universidade Federal do Rio Grande do Sul. Atua como professor e pesquisador na

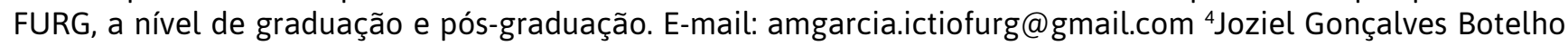
- Graduado em Ciências Biológicas, bacharelado, pela Universidade Federal do Rio Grande - FURG. Graduando em Ciências Biológicas, Licenciatura, pela FURG. E-mail: Joziel_bt@hotmail.com; 


\section{ABSTRACT}

Among the most common anthropic impacts on marine ecosystems and coastal, we can mention the installation of industries near the coastal zone, pollution, about fishing and habitat destruction. One way of problematizing and discussing how man is related with seas is promoting in the school environment an open space for debates, exposition of ideas and questionings. Seeking to develop different methodologies around coastal fishes with a focus on the dusky grouper (Epinephelus marginatus), which aim to stimulate the development of students with a critical reading of the reality of the municipality in which they live, making more profitable and enriching the teaching and learning process. In this context, the present work brings some discussions about how environmental education and extension has been placed in the university. Being the municipality of the Rio Grande/RS scenario of different environmental conflicts, it was sought to draw educational strategies that were in meeting to those problems which are closely related to students' experiences.

Key-Words: Anthropic impacts. Extension.Environmental conflicts

\section{INTRODUÇÃO}

A Educação Ambiental nos permite fazer um diálogo entre diversas áreas do conhecimento, vendo na natureza a possibilidade para conhecer cheiros, cores, gostos e um ótimo espaço para aprender e ressignificar o olhar do homem e sua integração com a natureza. A partir da contextualização podemos estimular o questionamento de ideias já postuladas, incentivar a curiosidade e o prazer pela descoberta buscando desmistificar as leis imutáveis construídas historicamente pela personificação do cientista6 .

Machado, Calonni e Adomillis discutem a maneira pela qual a Educação Ambiental Conservadora se contrapõe a uma prática educacional transformadora, que prime pela formação de cidadãos capazes de se posicionar e ter uma postura mais crítica, frente às necessidades da sociedade atual.

\footnotetext{
Essa perspectiva de um fazer transformador opõe-se a algumas formas dominantes de conceber a Educação Ambiental, no qual a natureza é abordada somente como recurso e as práticas educativo - pedagógicas são destinadas ao cumprimento de concepções técnicas e cientificas, para o que se entende como sendo o uso racional dos recursos naturais. (MACHADO; CALONNI; ADOMILLIS, 2016, p. 13-14, grifos nossos).
}

\footnotetext{
${ }^{6}$ Estereotipado como - aquele homem branco em laboratórios cheios de aparelhos tecnológicos inacessíveis para população de baixa renda, negros e mulheres -, justamente por não se enxergarem nesse personagem criado e reproduzido pela história, cultura e mídia.
} 
Para Steil e Carvalho (2014, p.164), "torna-se impossível dissociar a mente do corpo, a cultura da natureza, o conhecimento da experiência", quando procuramos relacionar as ciências da natureza com as ciências humanas, ciências da terra e até mesmo as ciências exatas, integrando a experiência dos saberes populares, das diversas culturas humanas, sejam dos povos extrativistas, da agricultura familiar, da capoeira ou do candomblé. Para estes autores, estamos desenvolvendo uma relação entre humanos e os não humanos e travando uma batalha contra a dualidade que existe entre natureza e cultura na sociedade, e, por conseguinte, na universidade e na escola.

Na cidade do Rio Grande, encontramos comunidades de pesca extrativista e grande diversidade de peixes, ambos por assim dizer, ameaçados de extinção. Fato este, desencadeado por inúmeros fatores que, no decorrer do artigo, tentaremos abordar. Todavia, levando em consideração este enquadramento, ainda hoje pouco se problematiza e se discute nas escolas do município acerca da cultura local e dos animais da região.

Podemos visualizar essa problemática por dois pontos de vista. O primeiro está relacionado à formação básica dos professores (as) da rede pública, que não os auxilia no aprofundamento de tais assuntos. O segundo é que a universidade não vem cumprindo o seu papel no desenvolvimento da extensão com a comunidade e a escola, o que contribui para essa lacuna na formação dos professores (as).

O principal material de ensino utilizado nas escolas é o livro didático no qual inexistem, com efeito, referências acerca dos animais do Bioma Pampa. Ao contrário disso, apresentam animais até mesmo de outros países ${ }^{7}$. Nessa condição, a aprendizagem é dada pela simples memorização de conteúdos por meio de repetições automáticas, que provavelmente serão lembrados somente para a realização de provas e depois esquecidas.

Nesse enquadramento, uma das maneiras de nos contrapormos a essa lógica bancária ${ }^{8}$ de aprendizagem, é contextualizarmos de forma multidisciplinar a Educação Ambiental, utilizando os procedimentos próprios do método científico na escola, dentre os quais, "observar, formular hipóteses, experimentar, registrar, sistematizar, analisar e criar" (PAVÃO, 2008, p. 15), na busca de despertarmos o prazer da descoberta estimulando a curiosidade,a fim de formarmos cidadãos com um olhar mais atento para com a natureza e as necessidades da sociedade atual.

Partindo do princípio de que ainda hoje o principal material de ensino utilizado nas escolas é o livro didático, notamos a importância da problematiza- 
ção da conservação ambiental, a partir de diferentes metodologias fundamentadas em peixes costeiros do Rio Grande, com enfoque na garoupa verdadeira (Epinephelus marginatus), devido a espécie estar ameaçada de extinção e ser comumente encontrada na costa gaúcha (CONDINI et al., 2010), compartilhando e recebendo saberes em uma experiência mútua com os estudantes na escola. Dentre essas distintas metodologias empregadas, os jogos educacionais surgiram no âmbito desse projeto, como uma forma reforçarmos o papel dos estudantes como protagonistas do processo de ensino e aprendizagem, além de desenvolvermos a socialização e o trabalho em grupo.

\section{OS DIFERENTES CONFLITOS AMBIENTAIS QUE SE ESTABELECEM EM RIO GRANDE}

Para Sartori (2010,p.127), "os diferentes problemas socioambientais parecem ser faces de uma mesma crise, movidos por uma mesma dinâmica”. Aparentemente a base dos problemas está na lógica do mercado capitalista9 ${ }^{9}$, que intensifica a crise ambiental, posto que seu propósito visa maximizar os lucros em nome do progresso, aumentando a produtividade com suas incansáveis buscas por novas tecnologias de produção.

É consenso entre os autores da Educação Ambiental Crítica que a educação reproduz a ideologia dominante. Vemos hoje na universidade brasileira ${ }^{10}$ uma inerente vocação para formar força de trabalho para satisfazer a demanda capitalista, enquanto há poucos estudos relacionados às necessidades da comunidade local e que buscam compreender as questões humanas, cooperando para a manutenção dos padrões hegemônicos. Como afirmam Rodrigues e Guimarães:

\footnotetext{
- Banco Mundial dita regras e as politicas educativas devem segui-las, a fim de adequarem-se aos padrões hegemônicos. Logo, a escola gera capital humano para atender o mercado, ao mesmo tempo em que o capital modifica as estruturas pedagógicas, quando se reconfigura para manter sua dominação (2010, p.18).
}

Nessa perspectiva, Marx e Engels (2006) já alertavam que o progresso busca homogeneizar o conhecimento, subordinando diferentes esferas consideradas predominantes, sendo a Universidade uma delas. Logo, o atual modelo de socie-

\footnotetext{
${ }^{9}$ Segundo Freire (2005), podemos resumir o capitalismo como uma sociedade de classes conflitantes e de interesses opostos, sendo uma minoria dominante e opressora. Essa minoria tem se apoderado de discursos sobre o meio ambiente, com um logo de "capitalismo verde" para promover o aumento da produtividade, consequentemente explorando a natureza e gerando inúmeros problemas socioambientais.

${ }^{10}$ Entendemos que a universidade está imersa em uma sociedade pautada na insustentabilidade do crescimento econômico, no consumismo e na extração que gera o esgotamento dos recursos naturais.
} 
dade e suas propostas para com a educação, não ajudam a formar novos conhecimentos, apenas servem para conservar e perpetuar a dominação da natureza e a exclusão social.

Nossa espécie é vitoriosa em descobertas e invenções tecnológicas, mas muito mal resolvida em questões que afetam a humanidade. Dessa forma, a "desigualdade socioeconômica estaria na origem da desigualdade ambiental, já que indivíduos e grupos sociais possuem acesso diferenciado a bens e amenidades ambientais" (LAYRARGUES, 2009, p. 18-19)11. Em síntese, podemos considerar que são desproporcionais e desiguais as consequências negativas do crescimento econômico, ficando sobre os grupos sociais despossuídos de recursos financeiros, educacionais, informacionais e políticos apenas os malefícios (ACSELRAD et al., 2012)

É nesse contexto que está situada a cidade do Rio Grande e os diferentes conflitos ambientais ${ }^{12}$ que nela se estabelecem diariamente e historicamente ${ }^{13}$, devido, sobretudo, a sua localização geográfica que facilita a movimentação industrial em prol do desenvolvimento e a custas de injustiças ambientais ${ }^{14}$. Visada por inúmeros empreendimentos com alto grau "poluidor" que atingem de forma cruel e desigual os grupos étnicos e raciais proporcionando uma baixa qualidade de vida às populações que residem próximas às instalações da refinaria de petróleo, indústrias de fertilizantes e indústria naval. Em uma reflexão elaborada por Santos e Machado (2013) originada através dos debates e pesquisas realizadas pelo Observatório dos Conflitos Urbanos e Socioambientais do Extremo Sul do Brasil vinculado à FURG eles definem Rio Grande como uma cidade

permeada de conflitos urbanos e ambientais, bem como de atividades potencialmente poluidoras, como: monoculturas (pinus, eucalipto, arroz e soja),pastagens para gado, indústria de fertilizantes, cadeia produtiva do petróleo (indústria naval e refinaria de petróleo), pesca industrial e outras, o que nos leva a considerá-la uma grande "zona de sacrifício" ou "paraíso de poluição" por ter, numa mesma localidade, uma série de indústrias e atividades potencialmente poluidoras" (SANTOS; MACHADO, 2013a, p.198-199).

\footnotetext{
${ }^{11}$ Podemos definir como amenidades ambientais: ar puro, áreas verdes, água limpa e risco ambiental como inundações, contaminações, poluição, desmoronamento e enchentes.

${ }^{12}$ Acselrad entende como conflitos ambientais: aqueles envolvendo grupos sociais com modos diferenciados de apropriação, uso e significação do território, tendo origem quando ao menos um dos grupos tem a continuidade das formas sociais de apropriação do meio que desenvolvem ameaçadas por impactos indesejáveis - transmitidos pelo solo, água, ar ou sistemas vivos decorrente do exercício das práticas de outros grupos (2004b, p. 26).

${ }^{13} \mathrm{~A}$ história do Rio Grande, desde a sua fundação foi marcada pelo recorrente enfrentamento do ser humano com a natureza, segundo as próprias concepções civilizatórias de então.

${ }^{14}$ Para Acselrad, podemos usar o termo injustiça ambiental para definir está situação em que "o mecanismo pelo qual sociedades desiguais, do ponto de vista econômico e social, destinam a maior carga dos danos ambientais do desenvolvimento às populações de baixa renda, aos grupos raciais discriminados, aos povos étnicos tradicionais, aos bairros operários, às populações marginalizadas e vulneráveis" (2009, p. 9).
} 
Atualmente contribuindo para esse cenário de "zona de sacrifício"15 situado na cidade temos o funcionamento de usinas de energia eólica que afetam a fauna, sobretudo, as aves, e também as populações próximas. Outra injustiça ambiental que acontece na região e que está diretamente ligada ao tema de discussão desse artigo é a proibição da pesca artesanal em algumas áreas do estuário da Lagoa dos Patos, onde a justificativa é o aumento do tráfego de grandes embarcações para o movimentado porto da cidade. O município impôs sobre as comunidades tradicionais está proibição sem negociações (GERHARDT et. al., 2014), sem debates ou discussões afetando diretamente o meio pelo qual os povos do mar sustentam suas famílias.

Por muito tempo, a economia de Rio Grande foi baseada na pesca, devido, principalmente, à localização geográfica da cidade. Portanto, os estudos sobre o ambiente aquático e costeiro na Universidade Federal do Rio Grande-FURG se desenvolveram de forma a buscar compreender a ecologia das espécies de peixes e crustáceos com importância econômica para a região (VANIEL et. al., 2006). Entretanto, os estudos ictiológicos ${ }^{16}$, levando em conta as comunidades tradicionais da cidade, são raros, mesmo sabendo-se da importância do conhecimento empírico, até mesmo para auxiliar no manejo e conservação das espécies. Para Massena e colaboradores (2014, p. 12), "os saberes sobre a natureza das populações locais são de suma importância para a valorização do conhecimento etnoictiológico ${ }^{17}$ e para a administração dos recursos naturais de forma adequada".

Aproximar a realidade da cidade do Rio Grande através da Educação Ambiental ao processo de ensino e aprendizagem, estimulando a criação de reflexões, debates e futuras ações, é tornar a escola um espaço democrático e a educação um exercício da cidadania. Paulo Freire (1996) diz que a educação não é responsável pela transformação social, mas que sem ela essa transformação não acontece. Sem embargo, a extensão se coloca como um espaço para promover e integrar diversas áreas do conhecimento, possibilitando a integração entre os estudantes, favorecendo a multidisciplinaridade e o desenvolvimento de uma consciência cidadã e humana. Contribuindo para a formação de sujeitos de mudança, capazes de se impor e se colocar com uma postura crítica na sociedade, trabalhando no sentindo da transformação social (CASTRO, 2004).

\footnotetext{
${ }^{15 “ C}$ Certas localidades destacam-se por serem objeto de uma concentração de práticas ambientalmente agressivas, atingindo populações de baixa renda. Os moradores dessas áreas convivem com a poluição industrial do ar e da água, solos contaminados etc. Verifica-se também uma tendência a sua escolha como sede da implantação de novos empreendimentos de alto potencialpoluidor. Tais localidades são chamadas, pelos estudiosos da desigualdade ambiental, de "zonas de sacrifício" ou "paraísos de poluição", onde a desregulação ambiental favorece os interesses econômicos predatórios (ACSELRAD, 2004a, p. 12-13, grifos nossos).

${ }^{16}$ Ramo da Zoologia dedicado ao estudo dos peixes.

${ }^{17} \mathrm{~A}$ Etnoictiologia procura compreender a interação entre homem e os peixes, buscando no conhecimento empírico auxílio para entender a ecologia e biologia dos peixes (BEGOSSI; FIGUEIREDO, 1995).
} 


\section{ENSINO, PESQUISA E EXTENSÃO: A DESCONSTRUÇÃO DESSE TRIPÉ NA UNIVERSIDADE}

A FURG, de acordo com seu Plano de Desenvolvimento Institucional (PDI) ${ }^{18}$,tem uma vocação voltada aos ecossistemas costeiros e oceânicos, por estar inserida em uma região costeira. Suas ações pautadas, segundo o artigo 207 da Constituição Brasileira de 1988, no princípio básico da indissociabilidade entre o ensino, a pesquisa e a extensão, busca compreender as necessidades locais ${ }^{19}$ regionais, nacionais e globais.

Nesse sentido, notamos hoje em dia a desconstrução deste discurso na prática, observando-se uma grande tendência à fragmentação deste tripé, desconsiderando a extensão e destacando as pesquisas, principalmente nas áreas biológicas, onde os conhecimentos produzidos pelos programas de pós-graduação são muitas vezes incompatíveis com a necessidade da sociedade e a comunidade local/regional.

Segundo Santos, tal tendência não seria exclusiva da universidade brasileira: "o conhecimento universitário [...] foi, ao longo do século XX, um conhecimento predominantemente disciplinar, cuja autonomia, impôs um processo de produção relativamente descontextualizado em relação às premências do cotidiano das sociedades"(2004, p. 40). Utilizando uma expressão usada pelo mesmo autor, gerou-se um conhecimento "para inglês ver". Moita e Andrade afirmam que "a indissociabilidade entre ensino, pesquisa e extensão ainda não é levada em conta na prática de muitos docentes, seja porque na graduação a ênfase recai sobre o ensino ou porque na pós-graduação acentua-se a pesquisa" (2009, p. 2). Vivemos em um mundo interdependente e cíclico, e neste sentido, a ciência contemporânea ${ }^{20}$ feita por especialistas com conhecimentos fragmentados, não conseguem abordar e muito menos resolver os diferentes problemas que afetam a humanidade em seus múltiplos seguimentos.

Como discutimos anteriormente, a universidade é uma esfera da sociedade considerada importante para homogeneização do conhecimento e perpetuação dos interesses do capitalismo, sendo assim, é esperado que os governantes e as agências de fomento não estimulem a extensão ${ }^{21}$.

\footnotetext{
${ }^{18}$ Disponível em:<http://www.pdi.furg.br/images/stories/documentos/pdi\%202015-2018\%20final. pdf $>$. Acesso em: 10 maio 2016.

${ }^{19}$ Desenvolvendo as inter-relações entre os organismos, incluindo o homem e o meio ambiente. ${ }^{20}$ Para Sartoriet,"a ciência contemporânea (atual) precisa ser reconfigurada , visto que um dos seus papéis" é fornecer conhecimentos para permitir uma melhor formulação e seleção das políticas de meio ambiente e desenvolvimento no processo de tomada de decisões. Para cumprir o requisito em questão, é indispensável desenvolver o conhecimento baseado em um novo paradigma, ou seja, uma nova forma de ver e pensar a realidade (SARTORI et al., 2010, p.10, grifos nossos).
} 
Porém, acreditamos que o princípio da indissociabilidade deve ser praticado pelos docentes, para que a extensão e a pesquisa se tornem consequências naturais da docência, favorecendo e fortalecendo a universidade (MOITA et. al., 2009), enriquecendo a formação docente e consequentemente o processo de ensino e aprendizagem.

A partir de pesquisas com a garoupa-verdadeira (Epinephelus marginatus), acreditamos que é possível desenvolver diferentes metodologias para problematizar a conservação marinha através da Educação Ambiental, levando o método científico adaptado à escola, estimulando a curiosidade, os questionamentos e a formulação de respostas através da observação da natureza; dos sons, toques, cheiros e gostos que ela produz. Além de desafios ${ }^{22}$, artefatos culturais ${ }^{23}$ e dinâmicas, auxiliando os estudantes a produzirem significados sobre a importância do equilíbrio da natureza e os aproximando da realidade do município em que vivem (QUADRADO et al., 2015).

\section{CAMINHOS METODOLÓGICOS E DESENVOLVIMENTO}

Realizamos uma oficina na Escola Dr. José Mariano de Freitas Beck - CIEP, tendo $\circ 6^{\circ}$ ano do ensino fundamental como público alvo. A escola está localizada no bairro São João na cidade do Rio Grande. A escolha desta instituição se deu por dois motivos: o primeiro é por sua gestão estar sempre buscando palestras, projetos e oficinas que visam trazer informações e trocas de experiências relacionadas ao cotidiano dos estudantes; o segundo é por possuir alguns estudantes que têm contato direto com a pesca devido aos familiares serem pescadores artesanais.

Inicialmente, visitamos a escola CIEP para fazer o convite à turma do $6^{\circ}$ ano, aproveitando a oportunidade para conhecer um pouco dos estudantes e os ambientes da escola. A oficina foi desenvolvida em quatro encontros diferentes. No primeiro, realizamos uma conversa informal com os estudantes na sala de vídeo, com auxílio de slides, conduzida com uma série de questionamentos, cujo intuito era ter uma visão do que a turma conhecia sobre a localização geográfica privilegiada da cidade do Rio Grande para vida marinha. Trazendo um pouco da

\footnotetext{
${ }^{21}$ Já que a extensão busca de maneira geral auxiliar os diferentes problemas enfrentados pelas populações humanas e não produzir força de trabalho para girar o mercado capitalista.

22"Os desafios têm como objetivo desenvolver a habilidade de observar estruturas, conhecer as principais características dos animais através da morfologia, desenvolver a argumentação e vivenciar atividades em grupo." (NEVES; SCHWANTES,2017,p.4).

${ }^{23}$ Artefatos culturais podem ser entendidos como produções que se dão no contexto de uma cultura e que contém pedagogias culturais, constituindo lugares pedagógicos, ou seja, ensinam modos de ser e de se olhar para o mundo. De acordo com Steinberg: "[...] lugares pedagógicos são aqueles onde o poder se organiza e se exercita, tais como bibliotecas, TV, filmes, jornais, revistas, brinquedos, anúncios, videogames, livros, esportes etc." (1997, p. 102).
} 
história da cidade através de alguns ambientes conhecidos por eles e realizando discussões a partir desses, como os Molhes da Barra, Praia do Cassino e também o Estuário da Lagoa dos Patos, foram utilizadas charges para discutir e comentar os principais impactos ambientais que põem em risco a biodiversidade marinha e costeira da região.

Com uma imagem de diferentes peixes costeiros da cidade do Rio Grande, realizou-se questionamentos sobre quais animais eles conheciam, com intuito de desenvolver o terceiro encontro envolvendo espécies conhecidas pelos estudantes.

Após essas discussões, fomos para uma das salas da escola, onde realizamos uma dinâmica de teia trófica. A cada estudante foi entregue um ser vivo marinho que representava toda sua espécie. Fizemos um círculo com todos os participantes e deu-se início à atividade. Após todos os estudantes estarem interligados, foi contada uma história em que os animais marinhos eram mortos ou predados, conforme as ligações na cadeia que a própria turma fez, cortamos o barbante, fazendo assim a comparação com o meio ambiente (ecossistema). Para finalizar, cada estudante respondeu um breve questionário sobre aspectos gerais da ecologia da garoupa, como por exemplo: quantos anos vive, onde vive, do que se alimenta, etc...

No segundo encontro, com auxílio de slides, foi apresentada uma história em quadrinhos sobre a vida da garoupa. Essa história conta um pouco como "ela", a garoupa, veio parar em Rio Grande, o seu habitat preferido, sua alimentação, como ela é pescada e o risco que sua espécie vem correndo de extinção de uma forma descontraída e divertida. Os quadrinhos que faziam referência aos métodos de captura tinham um vídeo exemplificando os apetrechos utilizados na pesca. Os alunos se proporam a ler os quadrinhos e, ao final da história, fizemos uma discussão sobre o tema. Após essa etapa, formaram-se grupos de até quatro alunos e foi entregue a cada grupo um jogo - "Tabuleiro da Garoupa" -, que foi desenvolvido e emprestado pelo laboratório de ictiologia, cujo objetivo é apresentar conceitos básicos de conservação marinha, a partir do ciclo de vida da garoupa (PEREIRA et al., 2011).

Para o terceiro dia de oficina, elaborou-se desafios de observação a partir dos peixes que eles citaram no primeiro encontro (bagre, corvina, tainha, traíra, peixe espada, linguado e cascuda) estes se constituem de curtas histórias cotidianas com situações-problema nas quais os estudantes, reunidos em grupos, têm de analisar exemplares animais conservados em álcool para solucioná-lo.

Além de observar as características de cada espécie, os desafios possibilitam aproximar as vivências dos estudantes ao ambiente escolar. Essa atividade foi desenvolvida no laboratório de ciências, onde, novamente, foram divididos em grupos de até quatro alunos. A cada grupo foi entregue um desafio e uma bandeja com um ou dois peixes, dependendo do desafio. Nesse momento, fica- 
mos circulando entre os grupos, ajudando-os com questionamentos que podiam levar a possíveis conclusões. Conforme cada grupo foi finalizando a atividade, foram separadas duas bandejas com peixes marinhos de morfologia diferentes das mais "conhecidas" pela população em geral, como o peixe morcego, a rêmora e o peixe voador.

Após todos os grupos terem discutido e chegado a uma conclusão, cada um apresentou para turma seu desafio e explicou suas conclusões. A partir de questionamentos, foi problematizado como os cientistas descobrem resultados e, brevemente, a partir das respostas deles, como somos cientistas diariamente, bem como a importância de observar, registrar, questionar, analisar e formular respostas no dia a dia. Ao final, enfatizamos como podemos descobrir muito sobre a ecologia de um animal, especificamente dos peixes, observando aspectos relacionados à sua morfologia.

O último encontro foi a reutilização de materiais trazidos por alguns estudantes, juntamente a outros disponibilizados. A proposta foi discutirmos a importância do cuidado com a natureza e de como podemos retardar a geração de lixo reciclável, reutilizando-os como matérias para enfeites e adereços. Problematizamos também como os maiores poluidores dos ecossistemas aquáticos são as grandes empresas instaladas na cidade do Rio Grande. Alguns alunos fizeram peixes, outros crustáceos, cnidários, moluscos, pulseiras e tiaras de cabelo personalizadas. Para concluir, foram entregues aos alunos camisetas do Projeto Garoupa dos Molhes, fornecidas pelo laboratório de Ictiologia da FURG.

\section{RESULTADOS E DISCUSSÕES}

No primeiro encontro, quando foram apresentados os peixes costeiros, boa parte da turma conhecia a tainha, o bagre, corvina e o tubarão martelo, relatando que os três primeiros eram na maioria das vezes utilizados na alimentação. Observamos a importância do conhecimento empírico, a partir do momento em três, dos vinte estudantes, esses filhos de pescadores artesanais, reconheceram todos os peixes mostrados nas imagens. Quando conversamos sobre a localização e história do Rio Grande utilizando charges, o momento foi muito integrativo, e alguns estudantes compartilharam relatos do seu cotidiano.

Durante a dinâmica da teia trófica, realizamos discussões e a reflexão da importância do equilíbrio da natureza. Quanto ao questionário aplicado, a primeira pergunta foi: Você conhece uma espécie de peixe chamado garoupa? Já ouviu falar? Percebeu-se que a maioria dos estudantes não a conhecia. Podemos analisar essas respostas em que mais de $60 \%$ nunca ouviu falar na garoupa como um reflexo da desigualdade socioeconômica presente em Rio Grande, visto que esse peixe está representado na nota de 100 reais, além de quando era comercializada sua carne ser muito apreciada na culinária. 
No segundo encontro, a história em quadrinhos ajudou a compartilhar muitas características da ecologia da garoupa de uma forma descontraída e divertida, além de responder as dúvidas que surgiram após o questionário realizado no primeiro encontro. O retorno da turma relativamente à proposta apresentada foi muito interessante, no sentido em que muitos estudantes faziam comentários a cada quadrinho, comparando-os com as perguntas do questionário. Logo após, o jogo auxiliou a enfatizar aspectos relevantes que foram apresentados na história em quadrinhos, além de estimular o trabalho em grupo. Nesse encontro, os estudantes participaram coletivamente, demonstrando interesse pelas propostas.

No terceiro dia, o objetivo maior com os desafios foi deslocar o centro do ensino em laboratório do educador para o estudante. Observou-se que, após a entrega dos desafios a cada grupo, os estudantes ficaram interessados e curiosos, discutindo e debatendo entre eles. Os estudantes, cujos familiares são pescadores, já tinham muitos conhecimentos sobre os peixes e rapidamente responderam as respostas dos desafios, além de um deles compartilhar com a turma a lenda do peixe linguado. Algo que seria interessante de ser realizado é uma roda de conversa sobre as lendas e mitos da cidade do Rio Grande nas escolas, registrar e divulgar esse momento talvez confeccionar uma cartilha ou um folheto, haveria, com certeza, troca de conhecimentos entre os estudantes, socialização, além da valorização dos hábitos da cultura local.

Com a atividade de reutilização de materiais, foi problematizado assuntos relacionados à poluição, e consequentemente a relação que tal impacto imprime nos ecossistemas costeiros e oceânicos, afetando diretamente a fauna e a flora. Desta forma, percebeu-se o desenvolvimento de discussões entre os estudantes que proporcionaram uma relação de compreensão com o ambiente que os cerca.

\section{CONSIDERAÇÕES FINAIS}

O cenário ambiental em que se encontra a cidade do Rio Grande é alarmante, vemos cair sobre os despossuídos os principais riscos à saúde, causados pelo crescimento econômico e pelo setor portuário e industrial movimentado. Vemos espécies ameaçadas de extinção sendo pescadas em alto-mar sem nenhuma fiscalização, enquanto os pescadores artesanais pedem auxílio, alertando sobre a necessidade de políticas públicas mais rigorosas e direcionadas para o oceano ${ }^{24}$. Muitas vezes a interpretação do ambiente é favorecida graças a esse tipo de saber tradicional que possui um olhar especial e cuidadoso de como manejar e conservar os recursos pesqueiros, uma vez que convivem diariamente nesses espaços e dependem de sua manutenção para sustento e modo de vida. Destacamos que a escola é uma instituição que tem papel de destaque na produção de significados ao aluno sobre ciências, meio ambiente, sociedade, entre outros (MAGALHÃES et al., 2015). Portanto, é importante promover nesses locais 
discussões sobre problemáticas e temas atuais relacionados ao cotidiano da cidade do Rio Grande.

Não menos relevante é estimular os estudantes a reconhecer sua integração com a natureza, buscando despertar o sentimento de pertencimento, a valorização do lugar onde se vive a diversidade de seres, ecossistemas e culturas (CRIVELLARO et al., 2001). Ao longo do uso de diferentes metodologias, intentamos provocar a reconstrução do conhecimento de forma prazerosa, desenvolvendo a criatividade e a motivação dos estudantes, bem como propiciando momentos de integração.

Cremos que a garoupa possui um grande potencial para se tornar uma espécie promotora de ações de debate e conservação do ambiente costeiro. Esperamos que através da união de desafios, jogos, dinâmicas com as discussões, tenhamos conseguido estimular novos questionamentos nos estudantes em relação ao contexto ambiental da cidade do Rio Grande. Evidenciamos, assim, a importância da continuação e aprimoramento dessas oficinas em diferentes escolas da cidade, pois ações pontuais pouco surtem um efeito desejado.

\section{REFERÊNCIAS}

ACSSELRAD, Henri. Conflitos ambientais no Brasil. Rio de Janeiro: Relume-Dumará, 2004.

O que é justiça ambiental. Rio de Janeiro: Lamparina, 2009.

ACSELRAD, Henri et al.Desigualdade ambiental e acumulação por espoliação: o que está em jogo na questão ambiental? Coletivo Brasileiro de Justiça Ambiental. Ecadernos CES, n. 17, 2012, p. 164-183. Disponível em:<http://www.ces.uc.pt/ecadernos/media/ecadernos17/07.ColetivoBras.Pesq.DesigualdadeAmbiental.pdf>. Acesso em: 21 fev. 2017

BEGOSSI, A.; FIGUEIREDO, J.L. Ethnoichthyology of southern coastal fishermen: cases from Búzios Island and Sepetiba Bay (Brazil).Bulletinof Marine Science,Miami, v. 56, n.2, p. 682-689, 1995.

CASTRO,Luciana Maria Cerqueira. A universidade, a extensão universitária e a produção de conhecimentos emancipadores. In: REUNIÃO ANUAL DA ANPED, 27., 2004, Caxambu.Anais... Caxambu: ANPED, 2004.

\footnotetext{
${ }^{24} \mathrm{Os}$ pescadores artesanais alertam sobre o esgotamento dos principais recursos pesqueiros da Lagoa dos Patos que vão de encontro aos estudos realizados pela FURG. Visto que, espécies de peixes e camarão de importância econômica e comercial possuem ciclo de vida envolvendo desova em mar aberto.
} 
CONDINI, Mario Viniciuset al. Garoupa-verdadeira Mycteroperca marginata (Pisces, Serranidae) nos molhes da barra de Rio Grande. Cadernos de Ecologia Aquática, Rio Grande, v. 5, p. 23-30, 2010.

CRIVELLARO, Carla Valeria Leonini; MARTINEZ NETO, Ramiro; RACHE, Rita Patta. Ondas que te quero mar: educação ambiental para comunidades costeiras.Porto Alegre: Gestal, 2001.

FREIRE, Paulo. Pedagogia da autonomia: saberes necessários a prática educativa. São Paulo: Paz e Terra,1996.

Pedagogia do oprimido. 41. ed. Rio de Janeiro: Paz e Terra, 2005.

GERHARDT, Cleyton; LOPO, Rafael; SANTOS, Caio Floriano. Pólo Naval de Rio grande: ideologia neodesenvolvimentista, "alternativas infernais" e "autoritarismos tolerantes". In: ZHOURI, Andréa ; VALÊNCIO, Norma. Formas de matar, de morrer e de resistir: limites da resolução negociada de conflitos ambientais e garantia dos direitos humanos e difusos. Belo Horizonte: UFMG, 2014.

LAYRARGUES, P.P. A crise ambiental e suas implicações na educação. In: QUINTAS, J.S. (Org.) Pensando e praticando a educação ambiental na gestão do meio ambiente.2.ed. Brasília: IBAMA, 2002.

MACHADO, Carlos; CALLONI, Humberto; ADOMILLI, Gianpaolo. Olhares, pensares e fazeres sobre e na educação ambiental:reflexões sobre/desde os fundamentos ao campo atual brasileiro. In: Dossiê temático fundamentos da educação ambiental.v. 21, n. 1, 2016.

MAGALHÃES, JoanaliraCorpes; BARROS, Suzana Conceição. Artefatos culturais: pensando possiblidades de abordagem para ensino de ciências e biologia. In: RIBEIRO,P.R.C, MAGALHÃES,J.L. (Org). Ensino de ciências outros olhares, outras possibilidades. Rio Grande: FURG, 2014.

MARX, Karl Heinrich; ENGELS, Friedrich. A ideologia alemã. São Paulo: Martins Claret,2006.

MASSENA, Fábio dos Santoset al. Etnoictiologia dos pescadores artesanais da vila Cachoeira,llhéus - BA. In: Rev. Bras. Eng. Pesca, v. 7, p. 32-44, 2014.

MOITA, Filomena; ANDRADE, Fernando. Ensino-pesquisa-extensão:um exercício de indissociabilidade na pós-graduação. Revista Brasileira de Educação, v. 14, n. 41, maio/ago. 2009. 
PAVÃO, Antônio Carlos; FREITAS, Denise. Quanta ciência há no ensino de ciências. São Carlos: UFSCAR, 2008.

PLANO de desenvolvimento institucional Rio Grande: FURG, 2015. Disponível em: <http://www.pdi.furg.br/images/stories/documentos/pdi\%202015-2018\%20final. pdf >. Acesso em: 10maio 2016.

PEREIRA,Carolina Rodrigues. Desenvolvimento de jogo didático visando à promoção da garoupa-verdadeira Mycteropercamarginata como espécie-bandeira na conservação do ambiente marinho. Monografia, Especialização em Ecologia Aquática Costeira, FURG. 2011.

NEVES, Kerolen Rosa; SCHWANTES, Lavínia. Método científico aplicado ao ensino de vertebrados. In:Jornada Biológica, 19., 2017, Rio Grande.Resumos... Rio Grande: FURG, 2017.

QUADRADO, Raquel Pereiraet al. Ecos do sul:conhecer os ecossistemas costeiros é tri legal. Rio Grande: FURG. 2015.

RODRIGUES, Jéssica Nascimento; GUIMARÃES, Mauro. Políticas públicas e educação ambiental na contemporaneidade: uma análise crítica sobre a política nacional de educação ambiental (PNEA). In: Ambiente \& Educação. Rio Grande, v. 15, n. 2, 2010.

SANTOS, Boaventura de Sousa (Org.). Conhecimento prudente para uma vida decente. São Paulo: Cortez, 2004.

SANTOS, Caio Floriano; MACHADO, Carlos R. S. Extremo sul do Brasil: uma grande "zona de sacrifício" ou "paraíso de poluição". In: MACHADO, Carlos R.Set al. (Orgs). Conflitos ambientais e urbanos: debates, lutas e desafios.Porto Alegre: Evangraf, 2013.p. 181-204.

SARTORI, Renata Coelho; MONTEIRO, Arlete Assumpção. Da crise ambiental para uma abordagem ecossistêmica do conhecimento: os desafios do conhecimento científico contemporâneo. In: Ambiente \& Educação. Rio Grande, , v.15, n. 2, 2010.

STEIL, C.A; CARVALHO, I.C.M. Epistemologias ecológicas: delimitando um conceito.Mana, v. 20, n.1, p. 163-183, 2014.

STEINBERG, Shirley. Kindercultura: a construção da infância pelas grandes corporações. In: SILVA, L. H.; AZEVEDO, J. C.; SANTOS, E. (Orgs.). Identidade social e a construção do conhecimento. Porto Alegre: Secretaria Municipal da Educação, 1997. 
VANIEL, Berenice Vahl; BEMVENUTI, Marlise deA. Investigando os peixes nos livros didáticos de ciências do ensino fundamental.Cadernos de Ecologia Aquática, v. 1, n. 1, p. 1-14, 2006.

Data de recebimento: 29 de julho de 2017.

Data de aceite para publicação: 23 de agosto de 2017. 